\title{
Implementación de la planificación estratégica para empresas del sector automotriz en la ciudad de Santo Domingo de los Tsáchilas, Ecuador: Caso Importadora de Autorepuestos Mendoza
}

\section{Implementation of strategic planning for companies in the automotive sector in the city of Santo Domingo de los Tsáchilas, Ecuador: Case Import Autorepuestos Mendoza}

DOI: $10.46932 / \mathrm{sfjdv2n4-006}$

Received in: May 1st, 2021

Accepted in: Jun 30th, 2021

\section{Mikel Ugando Peñate}

Doctor en Economía, por la Universidad de Santiago de Compostela, España DEA en Programa Doctorado Convergencia Internacional en el Ámbito Financiero y Contable, por la Universidad de Vigo, España

Institución: Pontificia Universidad Católica del Ecuador, Sede Santo Domingo, Ecuador

Dirección: Vía Chone Km 2, Santo Domingo, Ecuador, CP: 230203

E-mail: upm@pucesd.edu.ec, ugando75@gmail.com

\section{Zinthya Danila Jurado Zamora}

Licenciatura en Comercio, por la Pontificia Universidad Católica del Ecuador, Sede Santo Domingo, Ecuador

Institución: Pontificia Universidad Católica del Ecuador, Sede Santo Domingo, Ecuador

Dirección: Vía Chone Km 2, Santo Domingo, Ecuador, CP: 230203

E-mail: zdjuradoz@ pucesd.edu.ec, danilazjz1996@hotmail.com

\section{Anthony Damian Cedeño Mendoza}

Licenciatura en Comercio, por la Pontificia Universidad Católica del Ecuador, Sede Santo Domingo, Ecuador

Institución: Pontificia Universidad Católica del Ecuador, Sede Santo Domingo, Ecuador

Dirección: Vía Chone Km 2, Santo Domingo, Ecuador, CP: 230203

E-mail: adcedenom@pucesd.edu.ec, anto9854@gmail.com

\section{RESUMEN}

La implementación de herramientas administrativas, tal como la planeación estratégica, permitió establecer directrices para un mayor conocimiento de la situación actual de la empresa, así como también, se identificaron las problemáticas y establecieron las metas a corto y largo plazo. De tal modo, la implementación de las etapas de la planificación estratégica a través de la formulación, implementación y evaluación, establecieron una orientación en cada uno de los puntos importantes de la institución, tales como el desarrollo de políticas de recuperación de cartera, proceso de reposición de inventario y llevar a cabo acciones que determinen el direccionamiento y foco estratégico de la empresa. La implementación de la estrategia a través del mapa estratégico, permitió identificar 11 objetivos multinivel direccionados dentro de la perspectiva financiera, cliente, procesos internos y crecimiento / aprendizaje, seguidamente se evaluó el nivel de cumplimiento de los objetivos implementados mediante el diseño del Balanced Scoredcard de 1er y 2do nivel, con ello dar cumplimiento a la visión general de la empresa.

Palabras clave: Estrategia de desarrollo; Método de planificación; Planificación estratégica; Vehículo automotor 


\begin{abstract}
The implementation of administrative tools, such as strategic planning, establishing guidelines for a greater understanding of the current situation of the company, as well as identifying problems and establishing short and long-term goals. In this way, the implementation of the stages of strategic planning through the formulation, implementation and evaluation, established an orientation in each of the important points of the institution, such as the development of portfolio recovery policies, process of inventory replenishment and carry out actions that determine the direction and strategic focus of the company. The implementation of the strategy through the strategic map, found 11 multilevel objectives directed within the financial perspective, customer, internal processes and growth / learning, then the level of fulfillment of the implemented objectives was evaluated through the design of the Balanced Scoredcard of 1 st and 2 nd level, thereby complying with the general vision of the company.
\end{abstract}

Keywords: Development strategy; Planning method; Strategic planning; Motor vehicle.

\title{
1 INTRODUCCIÓN
}

En los últimos años las empresas del sector automotriz a nivel mundial, se han visto obligadas a realizar cambios en su estructura organizacional, para estar acorde al mundo competitivo actual y prepararse ante acontecimientos repentinos, que afecten las actividades de estas organizaciones como son los aspectos políticos, económicos, sociales, tecnológicos y legales. Por consiguiente, la implementación de la planificación estratégica en empresas dedicadas a la comercialización de partes y piezas de vehículos, es de vital importancia para que existan mejoras, mismas que contemplan los objetivos, políticas, reglas y demás recursos de la empresa los cuales permitirán competir en el mercado automotriz.

Para ampliar el discernimiento de la implementación de esta herramienta administrativa, se realizó una investigación en fuentes secundarias, y es así que, un estudio realizado en México a las PYMES manufactureras de Baja California, se determinó que las empresas de este sector enfrentan un problema debido a la alta competencia por el gran número de empresas existentes. Es así, que se llevó a cabo una investigación mediante un modelo de competitividad sistemática, el cual dio como resultados que dichas entidades son medianamente competitivas, pero con tendencia significativa a descender, lo cual repercute con su productividad. Este trabajo se desarrolló de manera descriptiva, correlacional, de forma transversal para analizar los factores que influyen en el nivel de competitividad .

Además, en la ciudad de Bogotá - Colombia, se llevó a cabo la implementación de la planificación estratégica y niveles de competitividad en pequeñas y medianas empresas del sector comercial, con el fin de proyectar estrategias competitivas a mediano y largo plazo en el mercado internacional debido a que en estas organizaciones existen problemas de gestión de recursos humanos, implementación de estrategias, entre otros. El presente estudio se analizó bajo una investigación de tipo descriptivo-analítica de manera transversal. Posteriormente, reflejó como resultados una mejora en los procesos de gestión para alcanzar niveles altos de competitividad en el mercado internacional . 
Así mismo, en el Ecuador se desarrolló una investigación sobre la aplicación de planificación estratégica en las pequeñas y medianas empresas de Quito, para determinar el nivel de inclusión y aplicación en la realidad de este tipo de organizaciones. Este estudio se orientó a través del método cuantitativo, tipo exploratorio transversal, del cual se obtuvo como resultado que el $94 \%$ de 267 empresas analizadas, tienen por escrito un plan estratégico, y únicamente el $22 \%$ de estas organizaciones lo implementan de manera integral. De tal modo, las investigaciones presentadas anteriormente indican que la implementación de la planificación estratégica y sus técnicas, contienen resultados significativos dentro de niveles administrativos y operativos de las empresas.

Una situación distinta sucede en la empresa Importadora de Autorepuestos Mendoza, ubicada en Santo Domingo de los Tsáchilas, la cual durante 8 años ha comercializado piezas y partes de vehículos, presentando problemas debido a la falta de políticas de recuperación de cartera, inexistencia de procesos para la reposición de inventario, una inadecuada delimitación de funciones y recursos, desconocimiento de implementación de estrategias administrativas y las acciones necesaria para lograr objetivos. Así como, la falta de un direccionamiento estratégico y un foco estratégico definido.

Es así que, la implementación de un modelo de planificación estratégica brindará posibles soluciones a las problemáticas establecidas, de tal manera que, un diagnóstico situacional de evaluación interna y externa, permitirá identificar factores importantes para la determinación de objetivos y la elaboración de un mapa estratégico. Los mismos que serán medibles y controlables por medio de indicadores financieros y no financieros, para el alcance de la estrategia. Estos criterios concuerdan con los resultados obtenidos por Valladares, Sánchez, Ugando, Sabando y Villalón (2021).

\section{REVISIÓN DE LITERATURA}

\subsection{SECTOR AUTOMOTRIZ EN EL CONTEXTO DE LAS PYMES}

Según Cremades \& Bianchi (2016) mencionan que "el sector automotriz es el que se ocupa del diseño, producción y ventas de automóviles, así como de sus partes y recambios o repuestos” (p.7). Por consiguiente, el sector automotriz es considerado como una cadena de producción, en donde se encuentran inmersas un conjunto de organizaciones que se dedican desde la producción de partes piezas e insumos, hasta la fabricación de maquinarias y vehículos.

\subsection{Planificación estratégica en el contexto empresarial}

La planificación estratégica es considerada como una herramienta la cual permite a las empresas formular e implementar estrategias basadas en los objetivos establecidos por la organización, con el fin de obtener una ventaja competitiva. Es así que, Davara (2015) indica que "uno de los padres de la planificación estratégica moderna, Igor Ansoff, la define como un proceso de decisión que debe conducir a seleccionar las estrategias a poner en práctica con objeto de alcanzar los objetivos establecidos” (p.195). 


\subsection{Modelo de la planificación de Fred David}

Según David (2013) manifiesta que "este modelo no garantiza el éxito, pero sí constituye un método claro y práctico para formular, implementar y evaluar las estrategias" (p.13). Por consiguiente, el modelo de planificación estratégica del presente autor, se encuentra dividido en tres etapas, las cuales son: formulación, implementación y evaluación de estrategias, este modelo se caracteriza por ser completo y conciso.

\subsubsection{Formulación de la estrategia}

La formulación de la estrategia es una de las etapas más significativas de la planificación estratégica, esta fase establece las herramientas y técnicas que la organización pretende desarrollar, misma que se genera en un lapso de tiempo menor a un año. Por tanto, Gutiérrez \& Gutiérrez (2018) señala que "La formulación de estrategias se realiza en un periodo corto de tiempo, normalmente menos de un año, ya que se trata de estudios sobre el papel. Esta fase es la que propiamente debe llamarse de planeación estratégica" (p.22).

\subsubsection{Implementación de la estrategia}

Según David (2013) señala que "significa movilizar tanto a empleados como a directivos para poner en práctica las estrategias formuladas. Considerada a menudo como la etapa más difícil de la administración estratégica, la implementación requiere de disciplina, compromiso y sacrificio" (p.6). De tal manera que, la implementación de la estrategia se considera la etapa con mayor dificultad, ya que depende del compromiso y trabajo de cada individuo que forme parte de la organización, de modo que pueda proporcionar su mayor esfuerzo en cada actividad propuesta en la formulación de la estrategia.

\subsubsection{Evaluación de la estrategia}

La evaluación de la estrategia permite a una organización diagnosticar y detectar oportunamente situaciones negativas a tiempo, es por ello que se pretende alertar a los encargados de la empresa para que la situación sea controlada sin mayores consecuencias. Por tanto, David (2013) indica que "Es vital para el bienestar de una organización; las evaluaciones oportunas pueden alertar a la gerencia de los problemas o los posibles problemas antes de que la situación se vuelva crítica” (p.287)

Según Villa, Pons, Bermúdez \& Pérez (2020) señalan que "En cualquier tipo de organización, pero fundamentalmente en las prestadoras de servicios, la Gestión por Competencias tiene una gran importancia. Sin embargo, la gestión de las competencias requiere de su medición y control” (p.1135). De tal modo, el Balanced Scoredcard es el medio estratégico idóneo para establecer una escala de control y cumplimiento. 
Es así que, Carvajal, Almeida, Lemoine, Caicedo, Zambrano, Subía, Pisco \& Nogueira (2021) indican que "Muchas personas piensan que los indicadores son una herramienta para controlar el comportamiento y para evaluar la actuación pasada. No debemos verlos solo así, sino incorporados al Cuadro de Mando Integral (CMI) para articular y comunicar la estrategia empresarial, la estrategia del negocio y para coordinar y alinear las iniciativas individuales de la organización y la de sus múltiples departamentos a fin de conseguir un objetivo común" (p.2457).

\section{MATERIALES Y MÉTODOS}

La presente investigación está orientada hacia un enfoque mixto. Conformado por la parte cuantitativa, la cual permite analizar datos en base al análisis estadístico. De la misma forma, se establece una parte cualitativa, que permitirá analizar resultados de cuestionarios, definir la población e identificar criterios de la muestra

El diseño del presente estudio es de tipo no experimental, de tal modo, se basa en observar y analizar fenómenos sin manipularlos. Con lo dicho anteriormente, este diseño se evidenciará en el proceso de recolección de datos para identificar factores internos y externos que determinan el funcionamiento de la empresa. También cuenta con el diseño exploratorio, el cual inicia con la recolección de información cualitativa, después sigue el proceso a través de la selección y análisis cuantitativos .

En el presente estudio se empleó una investigación descriptiva, la cual permite detallar fenómenos y situaciones a través de un análisis . De tal manera, a través de un diagnostico situacional, se recolectará información mediante factores internos, como el análisis financiero y la cadena de valor, así también de factores externos, como factores PESTEL y las fuerzas competitivas de Michael Porter, así mismo, se aplicarán técnicas de obtención de datos a clientes internos y externos para analizar su percepción sobre la organización.

\section{RESULTADOS}

4.1 ANÁLISIS DE FACTORES INTERNOS, EXTERNOS, DECLARACIÓN DE MISIÓN Y VISIÓN PARA LA EMPRESA “IMPORTADORA DE AUTOREPUESTOS MENDOZA”

Para la identificación de los factores internos, se analiza la situación financiera de la empresa. Es así que, dentro del análisis vertical de la cuenta de activos, la subcuenta de efectivo y equivalentes, contribuye al total activos 39,64\%; 30,56\%; 41,67\% y 60,78\% que corresponden desde el año 2016 al 2019. Para el análisis horizontal, existe una disminución de -18,34\% (2016-2017), el cual se ve influenciado por la cuenta de inventario de mercadería, presentando un incremento de 20,60\%. De la 
misma forma, entre el 2018-2019 se evidencia un decremento para la cuenta de inventario en mercadería de $-71,84 \%$, esta variante se refleja en el aumento de $50,26 \%$ de la cuenta de efectivo y equivalente.

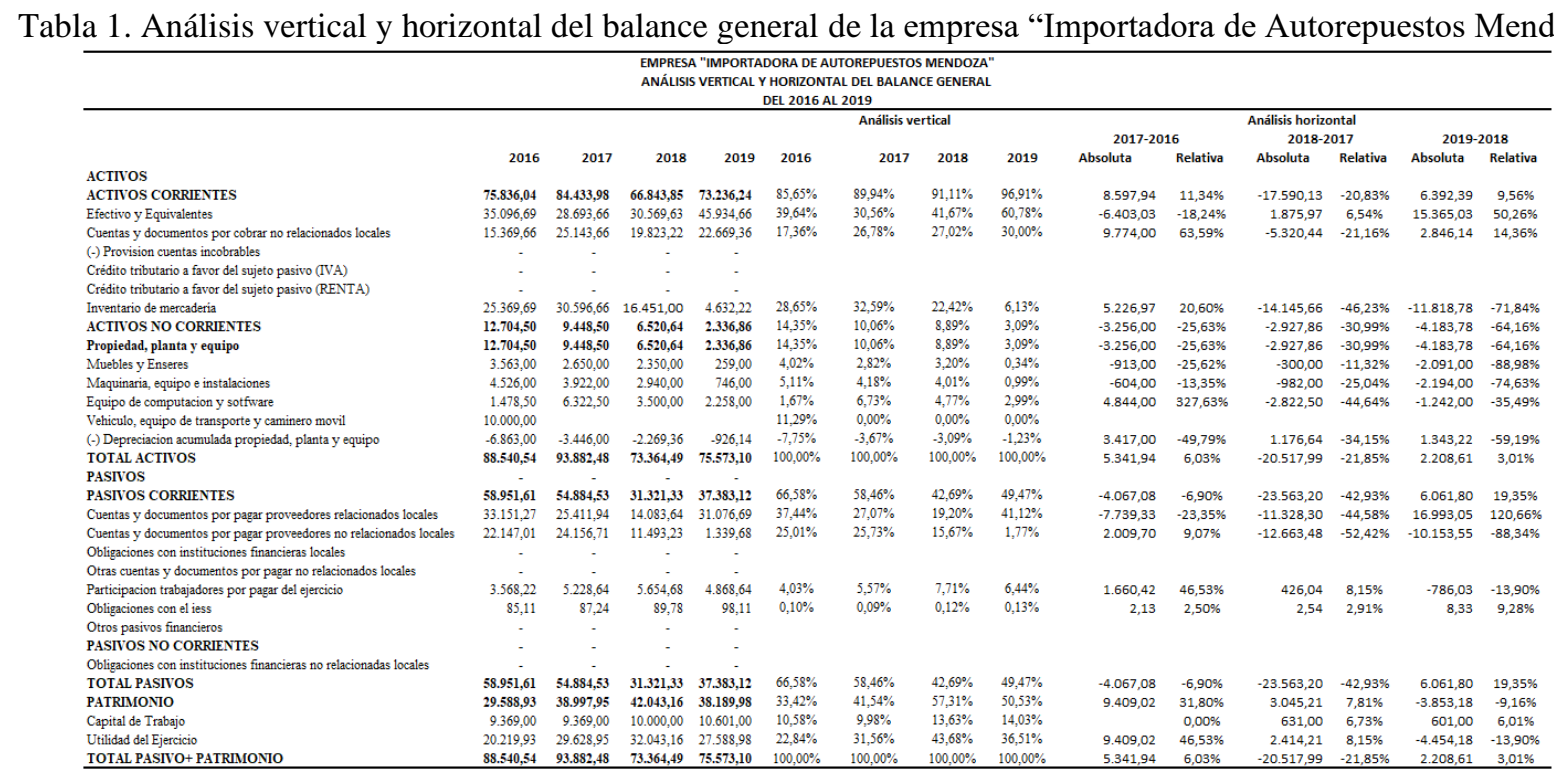

Fuente: Datos obtenidos de la investigación "Importadora de Autorepuestos Mendoza"

Así mismo, en referencia a la cuenta de pasivo, el análisis vertical de las cuentas y documentos por pagar proveedores relaciones locales contribuyen al total pasivo $37,44 \% ; 27,07 \% ; 19,20 \%$ y $41,12 \%$ que corresponden desde el año 2016 al 2019. En cambio, para el análisis horizontal existe una disminución de -23,35\% (2016-2017), posteriormente para el año 2018-2019 se refleja un aumento significativo de 120,66\%, esto debido a la reposición de inventario generado. Así mismo, la utilidad del ejercicio, subcuenta que corresponde a patrimonio, refleja un incremento proporcional de 46,53\% (2016-2017) y 8,53\% (2017-2018), por el contrario, para el año 2018-2019 se presenta una disminución de -13,90\%.

De la misma forma, en el estado de resultados, las ventas presentan un aumento de $21,35 \%$ (20162017), sin embargo, para el 2017-2018 disminuye en 8,35\% y finalmente para el 2018-2019 se refleja una recuperación de 15,17\%. Por su parte, la utilidad gravable, para el 2017 al 2018 indica un aumento 8,15\%, por el contrario, para el 2018-2019 disminuye en -13,90\%, debido al ajuste de compras ejecutada, lo cual se relaciona con la liquidación de inventario realizado. 
Tabla 2. Análisis vertical y horizontal de los estados de resultados de la empresa "Importadora de Autorepuestos Mendoza"

\begin{tabular}{|c|c|c|c|c|c|c|c|c|c|c|c|c|c|c|}
\hline \multicolumn{15}{|c|}{$\begin{array}{l}\text { EMPRESA "IMPORTADORA DE AUTOREPUESTOS MENDOZA" } \\
\text { ANÁLISIS VERTICAL Y HORIZONTAL DEL ESTADO DE RESULTADOS } \\
\text { DEL } 2016 \text { AL } 2019 \\
\end{array}$} \\
\hline & \multirow{2}{*}{2016} & \multirow[b]{2}{*}{2017} & \multirow[b]{2}{*}{2018} & \multirow{2}{*}{2019} & \multicolumn{4}{|c|}{ Análisis vertical } & \multirow{2}{*}{\multicolumn{2}{|c|}{ 2017-2016 }} & \multicolumn{2}{|c|}{$\begin{array}{l}\text { Análisis horizontal } \\
\text { 2018-2017 }\end{array}$} & \\
\hline & & & & & 2016 & 2017 & & 2019 & & & $\begin{array}{l}\text { 2018- } \\
\text { Absoluta }\end{array}$ & & $\begin{array}{l}2019-2 \\
\text { Absoluta }\end{array}$ & 2018 \\
\hline \multicolumn{15}{|c|}{ Relativa Absoluta Relativa Absoluta Relativa } \\
\hline Ventas & $123.659,66$ & $150.058,00$ & $162.589,69$ & $187.254,12$ & $100,00 \%$ & $100,00 \%$ & $100,00 \%$ & $100,00 \%$ & $26.398,34$ & $21,35 \%$ & $12.531,69$ & $8,35 \%$ & $24.664,43$ & $15,17 \%$ \\
\hline TOTAL NGGESOS & $123.659,66$ & $150.058,00$ & $162.589,69$ & $187.254,12$ & & & & & $26.398,34$ & $21,35 \%$ & $12.531,69$ & $8,35 \%$ & $24.664,43$ & $15,17 \%$ \\
\hline EGRESOS & & & & & & & & & & & & & & \\
\hline \multicolumn{15}{|l|}{ costos } \\
\hline Inventario inicial de bienes no producidos por el sujeto pasivo & $11.569,66$ & $25.369,69$ & $30.596,66$ & $16.451,00$ & $9,36 \%$ & $16,91 \%$ & $18,82 \%$ & $8,79 \%$ & $13.800,03$ & $119,28 \%$ & $5.226,97$ & $20,60 \%$ & $-14.145,66$ & $-46,23 \%$ \\
\hline Compras netas locales & $89.393,66$ & $101.693,66$ & $92.036,69$ & $121.938,04$ & $72,29 \%$ & $67,77 \%$ & $56,61 \%$ & $65,12 \%$ & $12.300,00$ & $13,76 \%$ & $-9.656,97$ & $-9,50 \%$ & $29.901,35$ & $32,49 \%$ \\
\hline (-) Inventario final de bienes no producidos por el sujeto pasivo & $-25.369,69$ & $-30.596,66$ & $-16.451,00$ & $-4.632,22$ & $-20,52 \%$ & $-20,39 \%$ & $-10,12 \%$ & $-2,47 \%$ & $-5.226,97$ & $20,60 \%$ & $14.145,66$ & $-46,23 \%$ & $11.818,78$ & $-71,84 \%$ \\
\hline $\begin{array}{l}\text { TOTAL COSTOS } \\
\text { GASTOS }\end{array}$ & $75.593,63$ & $96.466,69$ & $106.182,35$ & $133.756,82$ & $61,13 \%$ & $64,29 \%$ & $65,31 \%$ & $71,43 \%$ & $20.873,06$ & $27,61 \%$ & $9.715,66$ & $10,07 \%$ & $27.574,47$ & $25,97 \%$ \\
\hline Sueldos y salarios & $8.784,00$ & $9.000,00$ & $9.264,00$ & $9.689,76$ & $7,10 \%$ & $6,00 \%$ & $5,70 \%$ & $5,17 \%$ & 216,00 & $2,46 \%$ & 264,00 & $2,93 \%$ & 425,76 & $4,60 \%$ \\
\hline Beneficios sociales gravada del IESS & $2.562,00$ & $2.663,00$ & $2.718,00$ & $2.806,60$ & $2,07 \%$ & $1,77 \%$ & $1,67 \%$ & $1,50 \%$ & 101,00 & $3,94 \%$ & 55,00 & $2,07 \%$ & 88,60 & $3,26 \%$ \\
\hline Aporte a la seguridad social & $1.021,33$ & $1.046,84$ & $1.077,34$ & $1.177,31$ & $0,83 \%$ & $0,70 \%$ & $0,66 \%$ & $0,63 \%$ & 25,51 & $2,50 \%$ & 30,50 & $2,91 \%$ & 99,97 & $9,28 \%$ \\
\hline Honorarios a extranjeros por servic & $6.000,00$ & 600,00 & 600,00 & 600,00 & $4,85 \%$ & $0,40 \%$ & $0,37 \%$ & $0,32 \%$ & $-5.400,00$ & $-90,00 \%$ & & $0,00 \%$ & & $0,00 \%$ \\
\hline Mantenimiento y reparaciones & 589,63 & 369,66 & 252,63 & 808,80 & $0,48 \%$ & $0,25 \%$ & $0,16 \%$ & $0,43 \%$ & $-219,97$ & $-37,31 \%$ & $-117,03$ & $-31,66 \%$ & 556,17 & $220,15 \%$ \\
\hline Combustible y lubricantes & 825,52 & 712,55 & 614,25 & 772,26 & $0,67 \%$ & $0,47 \%$ & $0,38 \%$ & $0,41 \%$ & $-112,97$ & $-13,68 \%$ & $-98,30$ & $-13,80 \%$ & 158,01 & $25,72 \%$ \\
\hline Promocion y publicidad & 210,00 & 180,00 & 245,36 & 263,00 & $0,17 \%$ & $0,12 \%$ & $0,15 \%$ & 0,14 & $-30,00$ & $-14,29 \%$ & 65,36 & $36,31 \%$ & 17,64 & $7,19 \%$ \\
\hline Suministros, materiales y repuestos & 158,69 & 256,63 & 260,21 & 198,65 & $0,13 \%$ & $0,17 \%$ & $0,16 \%$ & 0,11 & 97,94 & $61,72 \%$ & 3,58 & $1,40 \%$ & $-61,56$ & $-23,66 \%$ \\
\hline Transporte & 452,69 & 396,66 & 225,36 & 237,75 & $0,37 \%$ & $0,26 \%$ & $0,14 \%$ & $0,13 \%$ & $-56,03$ & $-12,38 \%$ & $-171,30$ & $-43,19 \%$ & 12,39 & $5,50 \%$ \\
\hline \multirow{2}{*}{\multicolumn{15}{|c|}{$\begin{array}{l}\text { Intereses bancarios locales } \\
\text { Prevision }\end{array}$}} \\
\hline & & & & & & & & & & & & & & \\
\hline Arrendamiento mercantil local & $2.400,00$ & $2.400,00$ & $2.400,00$ & $2.688,00$ & $1,94 \%$ & $1,60 \%$ & $1,48 \%$ & $1,44 \%$ & & $0,00 \%$ & & $0,00 \%$ & 288,00 & $12,00 \%$ \\
\hline 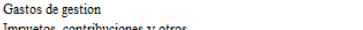 & & & & & & & & & & & & & & \\
\hline $\begin{array}{l}\text { Impuetos, contribuciones y otros } \\
\text { Depreciacion propiedd, planta }\end{array}$ & 180,36 & 121,69 & 86,69 & 90,61 & $0,15 \%$ & $0,08 \%$ & $0,05 \%$ & $0,05 \%$ & $-58,67$ & $-32,53 \%$ & $-35,00$ & $-28,76 \%$ & 3,92 & $4,52 \%$ \\
\hline $\begin{array}{l}\text { Depreciacion propiedad, } \mathrm{p} \\
\text { Pago por otros servicios }\end{array}$ & 6 & 9 & 56 & & 0,5 & 0,3 & $0,35 \%$ & 0,41 & $-106,97$ & $-15,33 \%$ & $-21,03$ & $-3,56 \%$ & 196,62 & $34,52 \%$ \\
\hline Seguridad & 396,00 & 396,00 & 396,00 & 940,66 & $0,32 \%$ & $0,26 \%$ & $0,24 \%$ & $0,50 \%$ & & $0,00 \%$ & & $0,00 \%$ & 544,66 & $137,54 \%$ \\
\hline TOTAL GASTOS & $24.277,88$ & $18.733,72$ & $18.709,50$ & 21.039,68 & $19,63 \%$ & $12,48 \%$ & $11,51 \%$ & $11,24 \%$ & $-5.544,16$ & $-22,84 \%$ & $-24,22$ & $-0,13 \%$ & $2.330,18$ & $12,45 \%$ \\
\hline UTILIDAD DEL EJERCICIO & $23.788,15$ & $34.857,59$ & $37.697,84$ & $32.457,62$ & $19,24 \%$ & $23,23 \%$ & $23,19 \%$ & $17,33 \%$ & $11.069,44$ & $46,53 \%$ & $2.840,25$ & $8,15 \%$ & $-5.240,22$ & $-13,90 \%$ \\
\hline $15 \%$ Participación trabajadores & $3.568,22$ & $5.228,64$ & $5.654,68$ & $4.868,64$ & $2,89 \%$ & $3,48 \%$ & $3,48 \%$ & $2,60 \%$ & $1.660,42$ & $46,53 \%$ & 426,04 & $8,15 \%$ & $-786,03$ & $-13,90 \%$ \\
\hline UTLIDAD GRAVABLE & $20.219,93$ & 29.628,95 & $32.043,16$ & $27.588,98$ & $16,35 \%$ & $19,74 \%$ & $19,71 \%$ & $14,73 \%$ & $9.409,02$ & $46,53 \%$ & $2.414,21$ & $8,15 \%$ & $-4.454,18$ & $13,90 \%$ \\
\hline
\end{tabular}

Fuente: Datos obtenidos de la investigación "Importadora de Autorepuestos Mendoza"

La empresa en las razones financieras cuenta con una liquidez para el año 2018-2019 con \$2,13 y \$1,96 respectivamente, siendo una situación favorable, ya que, por cada dólar en el pasivo corriente, la empresa tiene a disposición \$2,13 y \$1,96. Así mismo, estos valores se ratifican en el estado de fuente y uso dentro de la cuenta efectivo y equivalentes que representa un cambio de $\$ 15.365,03$. De la misma forma, tiene una deuda total para el 2018-2019 de \$0,43 y \$0,49 lo que implica una porción no significativa de deuda, lo que permite cubrir sus obligaciones con capital propio, esto se ratifica en la cuenta y documentos por pagar proveedores relacionados locales obteniendo una fuente de $\$ 16.993,05$.

Figura 1. Razones financieras Importadora de Autorepuestos Mendoza
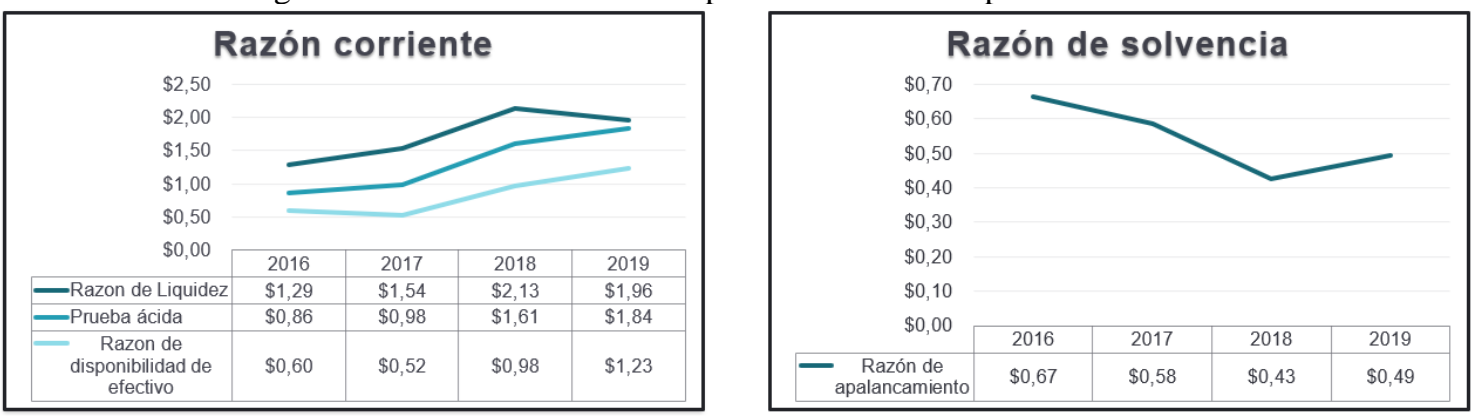

Fuente: Datos obtenidos de la investigación "Importadora de Autorepuestos Mendoza" 
Tabla 3. Estado de Fuente y uso "Importadora de Autorepuestos Mendoza"

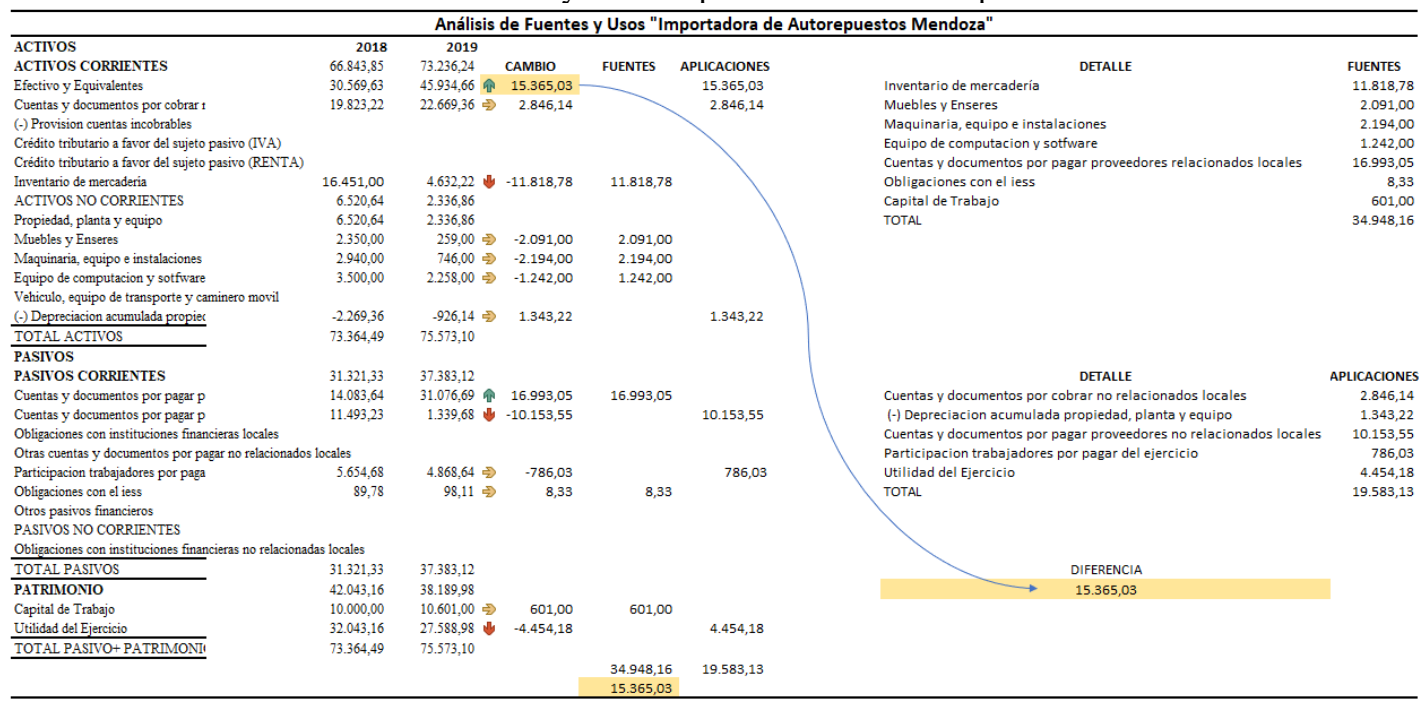

Fuente: Datos obtenidos de la investigación "Importadora de Autorepuestos Mendoza”

Dentro de la cadena de valor, se presentan cuatro procesos dentro de los niveles de apoyo y siete funciones correspondientes a las actividades primarias, en las que destacan que no existe una planificación estratégica en procedimiento y actividades, no cuenta con infraestructura propia, así como también, no disponen de un registro constante de la mercadería lo que genera confusión y retraso en su búsqueda. Sin embargo, para el abastecimiento y compras, la empresa cuenta con proveedores locales que permiten abastecerse de manera continua, y la existencia de garantías solo en el caso de repuestos originales.

El ciclo de vida del producto, permitió identificar cinco líneas en su cartera de productos, sistema de transmisión, motor, dirección, alimentación y enfriamiento. Para el año 2019, el sistema de transmisión representó el 52\% en la totalidad de ventas, motor (32\%), dirección (11\%), alimentación (3\%) y de enfriamiento (2\%). Cabe destacar, que las tres primeras líneas de repuestos automotrices se encuentran en la etapa de crecimiento, por la amplia variedad de productos a disposición. Una situación distinta se presenta en el sistema de alimentación y enfriamiento, ya que se mantienen en la etapa de introducción, debido a que dentro de su cartera de productos existe un artículo disponible.

Tabla 4. Ciclo de vida del producto de la empresa "Importadora de Autorepuestos Mendoza" Venta anual por línea de repuestos automotrices

\begin{tabular}{crrrrrr}
\hline Línea de repuestos automotrices & $\mathbf{2 0 1 7}$ & & $\mathbf{2 0 1 8}$ & \multicolumn{2}{c}{$\mathbf{2 0 1 9}$} \\
\hline Sistema de transmisión & $\$ 78.030,16$ & $\$$ & $84.546,64$ & $\$$ & $97.372,14$ \\
\hline Sistema de motor & $\$ 448.018,56$ & $\$$ & $52.028,70$ & $\$$ & $59.921,32$ \\
\hline Sistema de dirección & $\$ 16.506,38$ & $\$$ & $17.884,87$ & $\$$ & $20.597,95$ \\
\hline Sistema de alimentación & $\$ 4.501,74$ & $\$$ & $4.877,69$ & $\$$ & $5.617,62$ \\
\hline Sistema de enfriamiento & $\$ 3.001,16$ & $\$$ & $3.251,79$ & $\$$ & $3.745,08$ \\
\hline TOTAL & $\$ 150.058,00$ & $\$ 162.589,69$ & $\$ 187.254,12$
\end{tabular}

Fuente: Datos obtenidos de la investigación "Importadora de Autorepuestos Mendoza" 
La empresa Importadora de Autorepuestos Mendoza, en su capacidad instalada, dispone con dos áreas de trabajo, mismas que comprenden, el área de almacenamiento, donde se realizan actividades de inventario y está estructurada en seis perchas por líneas de productos en 10,58 $\mathrm{m}^{2}$, este reducido espacio se encuentra utilizado al $100 \%$, lo que genera incomodidad en la búsqueda de un determinado artículo. Así mismo, el área de ventas con el 85\% de capacidad utilizada, dispone de una percha, vitrina de exposición y un reducido espacio de espera para los clientes, que representa 12,95 m² de área empleada.

Tabla 5. Capacidad instalada de la empresa "Importadora de Autorepuestos Mendoza"

\begin{tabular}{lccc}
\hline \multicolumn{1}{c}{ Área de la empresa } & $\mathrm{m}^{2}$ totales por área & $\mathrm{m}^{2}$ utilizados por área & Capacidad utilizada $(\%)$ \\
\hline Área de almacenamiento & $10,58 \mathrm{~m}^{2}$ & $10,58 \mathrm{~m}^{2}$ & $100 \%$ \\
\hline Área de ventas & $20,49 \mathrm{~m}^{2}$ & $18,24 \mathrm{~m}^{2}$ & $88 \%$ \\
\hline
\end{tabular}

Fuente: Datos obtenidos de la investigación "Importadora de Autorepuestos Mendoza”

Figura 2. Análisis FODA Importadora de Autorepuestos Mendoza

\section{Fortalezas}

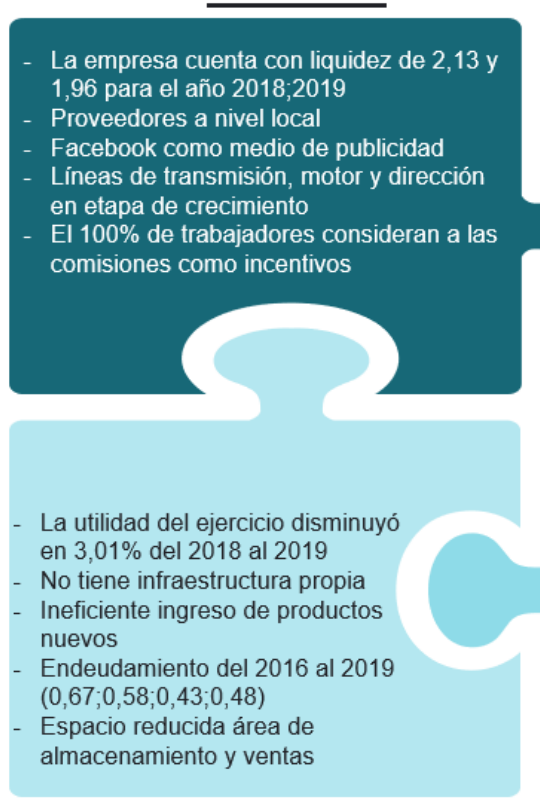

\section{Debilidades}

\section{Oportunidades}

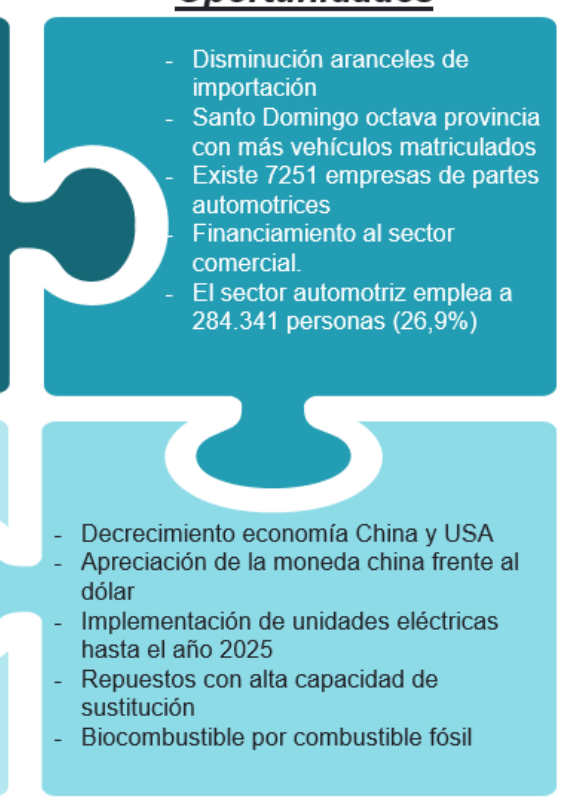

Amenazas

Fuente: Datos obtenidos de la investigación "Importadora de Autorepuestos Mendoza"

\section{Declaración de la misión:}

La Importadora de Autorepuestos Mendoza es una empresa dedicada a la comercialización de repuestos para vehículos livianos y pesados en la Provincia de Santo Domingo de los Tsáchilas, con un equipo de trabajo comprometido que actúa con respeto, puntualidad, responsabilidad. Enfocado en brindar al cliente una atención adecuada y óptima, así mismo, dispone de un amplio stock de productos con proveedores que establecen alto estándares de calidad.

\section{Declaración de la visión:}

Para el año 2025, la Importadora de Autorepuestos Mendoza será una empresa comercializadora de piezas automotrices para todo tipo de vehículos, consolidada en el mercado, con una amplia cobertura a nivel 
local y nacional, aumentando su cartera de productos a través de alianzas estratégicas con proveedores, e incrementando su utilidad a través de la apertura de un nuevo punto de venta e infraestructura propia.

4.2 ANÁLISIS DE LA ELABORACIÓN DEL MAPA ESTRATÉGICO PARA EL DESARROLLO DE LA PROPUESTA DE IMPLEMENTACIÓN DE OBJETIVOS ESTRATÉGICOS, ASÍ COMO DE POLÍTICAS Y REGLAS PARA EL ALCANCE DE LA ESTRATEGIA.

Tabla 6. Mapa estratégico para la empresa "Importadora de Autorepuestos Mendoza”.

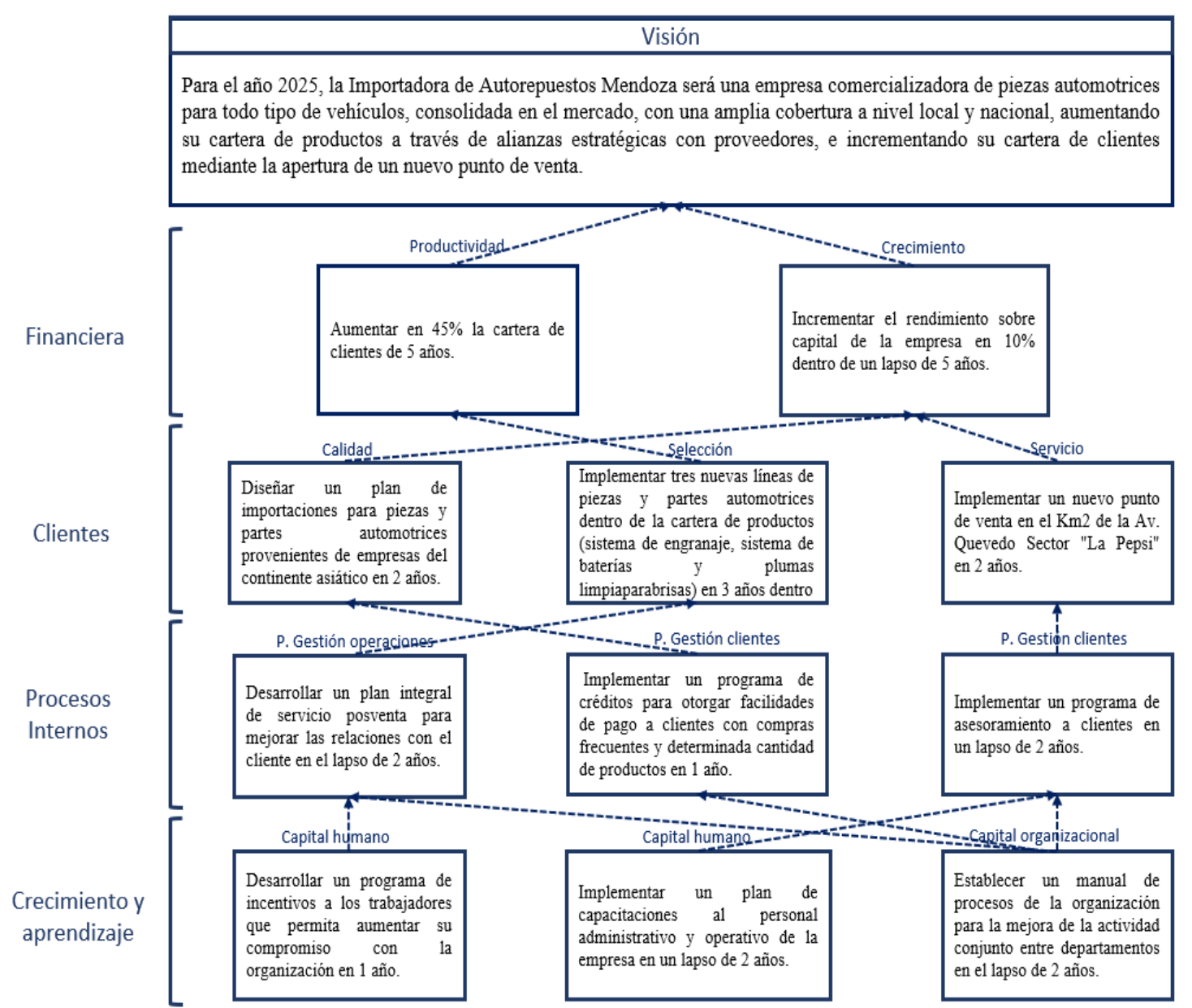

Fuente: Datos obtenidos de la investigación "Importadora de Autorepuestos Mendoza"

\subsection{ANÁLISIS DE LA PROPUESTA DE BALANCED SCOREDCARD DE 1ER Y 2DO NIVEL COMO HERRAMIENTA PARA LA EVALUACIÓN Y MEDICIÓN DE LOS OBJETIVOS MULTINIVEL.}

El Balanced Scoredcard es una herramienta administrativa que tiene como fin, establecer objetivos claves de éxito, iniciativas y metas, enlazarlos, medirlos a través de perspectivas que comprometen a toda la organización, enfocados en la parte, financiera, clientes, procesos internos y crecimiento/aprendizaje para el cumplimiento de la visión de la empresa. A continuación, se presenta el modelo de estrategias mediante la ejecución de BSC de 1er y 2do nivel para la empresa Importadora de Autorepuestos Mendoza. 
Tabla 7. Balanced Scoredcard ler nivel "Importadora de Autorepuestos Mendoza"

\begin{tabular}{|c|c|c|c|c|c|c|c|c|c|c|c|c|c|c|c|c|c|c|c|}
\hline \multirow{3}{*}{ Perspectivas } & \multicolumn{19}{|c|}{ PRIMER NIVEL } \\
\hline & \multicolumn{4}{|c|}{ AREA O UNIDAD } & & \multicolumn{14}{|c|}{ MEDIDAS } \\
\hline & \multicolumn{2}{|c|}{ Estrategia de Valor } & \multicolumn{3}{|c|}{ Objetivos Estratégicos } & \multicolumn{6}{|c|}{ KPI's } & \multicolumn{2}{|c|}{$\begin{array}{l}\text { Definición } \\
\text { Operacional }\end{array}$} & & $\begin{array}{l}\text { ecuencia d } \\
\text { actuación }\end{array}$ & \multicolumn{3}{|c|}{ Fuente de captura } & Nivel Base \\
\hline \multirow{2}{*}{$\begin{array}{l}\text { Perspectiva } \\
\text { Financiera }\end{array}$} & \multicolumn{2}{|c|}{$\begin{array}{l}\text { Estrategia de } \\
\text { productividad }\end{array}$} & \multicolumn{3}{|c|}{$\begin{array}{l}\text { Aumentar en } 45 \% \text { la cartera de clientes } \\
\text { dentro de } 5 \text { años. }\end{array}$} & \multicolumn{6}{|c|}{ Cartera de clientes =\# de clientes 2025} & \multicolumn{2}{|c|}{ Cartera de clientes } & & Anual & \multicolumn{3}{|c|}{ Informe de gerencia } & 1.039 \\
\hline & \multicolumn{2}{|c|}{$\begin{array}{l}\text { Estrategia de } \\
\text { crecimiento }\end{array}$} & \multicolumn{3}{|c|}{$\begin{array}{l}\text { Incrementar el rendimiento sobre capital } \\
\text { de la empresa en } 10 \% \text { dentro de un lapso } \\
\text { de } 5 \text { años. }\end{array}$} & \multicolumn{6}{|c|}{$\begin{array}{l}\text { Capital de la empresa= (Utilidad neta } \\
\text { 2025 / patrimonio 2025)-(Utilidad neta } \\
2020 \text { / patrimonio 2020)*100 }\end{array}$} & \multicolumn{2}{|c|}{ Capital de la empresa } & & Anual & \multicolumn{3}{|c|}{$\begin{array}{l}\text { Estado de situación } \\
\text { financiera / /stado de } \\
\text { resultados/Razones } \\
\text { financieras }\end{array}$} & lee \\
\hline \multirow{3}{*}{$\begin{array}{l}\text { Perspectiva de } \\
\text { cliente }\end{array}$} & \multicolumn{2}{|c|}{ Estrategia de calidad } & \multicolumn{2}{|c|}{$\begin{array}{l}\text { Diserarar un plan de importaciones } \\
\text { para piezas y partes automotrices } \\
\text { proveneientes de empresas del } \\
\text { continente asiatico en } 2 \text { años. }\end{array}$} & \multicolumn{7}{|c|}{$\begin{array}{l}\text { Plan de importación automotriz } 2021 \text { = (\# \#de } \\
\text { etapas } \\
\text { completadas / Total de etapasprogramadas) }\end{array}$} & \multicolumn{3}{|c|}{$\begin{array}{l}\text { Plan de importación } \\
\text { automotriz } 2022\end{array}$} & Anual & & nforme de 5 & gerencia & 0 \\
\hline & Estrategia de sel & lección & $\begin{array}{l}\text { Implementar tres nuevas lineas } \\
\text { piezas y partes automotrices de } \\
\text { de la cartera de productos sist } \\
\text { de engranaje, sistema de batert } \\
\text { plumas lijpiaparabrisas beria }\end{array}$ & & & $\begin{array}{l}\text { ortafolio } \\
\text { neas ent: } \\
\text { neas actu } \\
\text { empresa }\end{array}$ & $\begin{array}{l}\text { o de produ } \\
\text { la cartera } \\
\text { tuales de } \\
\text { sa }\end{array}$ & $\begin{array}{l}\text { uctos }=\# \\
\text { de prod }\end{array}$ & $\begin{array}{l}\text { \# Total de } \\
\text { \#uctos / \# } \\
\text { unat }\end{array}$ & $\begin{array}{l}\text { e nuevas } \\
\text { \# Total de } \\
\text { ntal }\end{array}$ & & $\begin{array}{c}\text { Portat } \\
\text { prod }\end{array}$ & folio de & & Anual & & nforme de 5 & gerencia & 5 \\
\hline & Estrategia de se & ervicio & $\begin{array}{l}\text { Implementar un nuevo punto d } \\
\text { venta en el Km2 de la Av. Quevv } \\
\text { Sector "La Pepsi" en } 2 \text { años. }\end{array}$ & & & $\begin{array}{l}\text { untos de } \\
\text { peración } \\
\text { pitotal d }\end{array}$ & $\begin{array}{l}\text { e venta }=\text { f } \\
\text { ne estable }\end{array}$ & $\begin{array}{l}\text { I de esta } \\
\text { ecimiento }\end{array}$ & $\begin{array}{l}\text { ablecimier } \\
\text { os de la es }\end{array}$ & entos en & & Puntos & de venta & & Anual & & nforme de $\mathrm{g}$ & gerencia & 0 \\
\hline & $\begin{array}{r}\text { Estrategia de ge } \\
\text { operativa }\end{array}$ & $\begin{array}{l}\text { estión } \\
\text { ea }\end{array}$ & $\begin{array}{l}\text { Desarrollar un plan integral de } \\
\text { servicio posventa para mejorar } \\
\text { relaciones con el cliente en el la } \\
\text { de } 2 \text { años. }\end{array}$ & & & $\begin{array}{l}\text { nplement } \\
\text { anes } \\
\text { eservicio }\end{array}$ & ntación pl: & an servic & cio post ve & $\begin{array}{l}\text { venta }=\# \text { c } \\
\text { os }\end{array}$ & & $\begin{array}{l}\text { mplemen } \\
\text { servicio }\end{array}$ & $\begin{array}{l}\text { tación plan } \\
\text { post venta }\end{array}$ & & Anual & & nforme de $\mathrm{g}$ & gerencia & 0 \\
\hline $\begin{array}{l}\text { Perspectiva } \\
\text { Interna }\end{array}$ & $\begin{array}{r}\text { Estrategia de ge } \\
\text { de cliente }\end{array}$ & e & $\begin{array}{l}\text { Implementar un programa de } \\
\text { créditos apara otorgar facilididade } \\
\text { pago a clientes con compras } \\
\text { frecuentes y determinada canti } \\
\text { de productos en } 1 \text { año. cant }\end{array}$ & & & $\begin{array}{l}\text { rograma } \\
\text { esarrollat } \\
\text { de moddu }\end{array}$ & $\begin{array}{l}\text { de crédit } \\
\text { alos / } \\
\text { ulos del p }\end{array}$ & os $=(\# c$ & de módulc & & & rograma & de créditos & & Anual & & nforme de $\mathrm{g}$ & gerencia & 0 \\
\hline & $\begin{array}{r}\text { Estrategia de ge } \\
\text { de cliente }\end{array}$ & $\begin{array}{l}\text { estión } \\
\text { e }\end{array}$ & $\begin{array}{l}\text { Implementar un programa de } \\
\text { asesoramiento a clientes en un } \\
\text { de } 2 \text { años. }\end{array}$ & lapso & & $\begin{array}{l}\text { regrama } \\
\text { tapas de } \\
\text { sesorami } \\
\text { de etapa }\end{array}$ & $\begin{array}{l}\text { de aseso } \\
\text { ieento ejec } \\
\text { as de ases }\end{array}$ & $\begin{array}{l}\text { ramientc } \\
\text { cutadas } \\
\text { soramien }\end{array}$ & $\begin{array}{l}\text { to clientes } \\
\text { nto asigna }\end{array}$ & ls= (\# de & & $\begin{aligned} \begin{array}{l}\text { Progr. } \\
\text { asesor. } \\
\text { clie }\end{array} & \end{aligned}$ & $\begin{array}{l}\text { ama de } \\
\text { amiento } \\
\text { entes }\end{array}$ & & Anual & & nforme de $\mathrm{g}$ & gerencia & 0 \\
\hline & $\begin{array}{l}\text { Estrategia de ca } \\
\text { humano }\end{array}$ & capital & $\begin{array}{l}\text { Desarrollar un programa de } \\
\text { incentivos a los trabajajodores qu } \\
\text { permita aumentar sucomprom } \\
\text { con la organizizacíón en } 1 \text { año. }\end{array}$ & & & $\begin{array}{l}\text { esarrollo } \\
\text { rogramas } \\
\text { centivos } \\
\text { cogramas } \\
\text { e incentiv }\end{array}$ & $\begin{array}{l}\text { o program } \\
\text { is de } \\
\text { s a trabaja } \\
\text { is } \\
\text { ivos a trat }\end{array}$ & $\begin{array}{l}\text { pa de inc. } \\
\text { adores de } \\
\text { bajadore. }\end{array}$ & $\begin{array}{l}\text { entivos }= \\
\text { tesarrollac } \\
\text { es planific }\end{array}$ & $\begin{array}{l}=(\#) \\
\text { cados } / \# \\
\text { cados })\end{array}$ & & $\begin{array}{l}\text { Desarrollc } \\
\text { de inc }\end{array}$ & $\begin{array}{l}\text { o programa } \\
\text { eentivos }\end{array}$ & & Anual & & nfforme de $\mathrm{g}$ & gerencia & 0 \\
\hline Perspectiva de & $\begin{array}{c}\text { Estrategia de ca } \\
\text { humano }\end{array}$ & capital & $\begin{array}{l}\text { Implementar un plan de capacin } \\
\text { personal administratvo y opera } \\
\text { empresa en un lapso de } 2 \text { años. }\end{array}$ & $\begin{array}{l}\text { taciones: } \\
\text { tivo de la } \\
\text { tat }\end{array}$ & \begin{tabular}{l|l} 
al \\
a
\end{tabular} & $\begin{array}{l}\text { lan de ca } \\
\text { esarrolla } \\
\text { \# de móc }\end{array}$ & $\begin{array}{l}\text { apacitacio } \\
\text { gdos } \\
\text { idulos del }\end{array}$ & ones $=(\#)$ & \# de módu & & & $\begin{array}{c}\text { Pla } \\
\text { capaci }\end{array}$ & $\begin{array}{l}\text { in de } \\
\text { taciones }\end{array}$ & & Anual & & nforme de s & gerencia & 0 \\
\hline & $\begin{array}{l}\text { Estrategia de cu } \\
\text { organizacion }\end{array}$ & $\begin{array}{l}\text { Euttura } \\
\text { nnal }\end{array}$ & $\begin{array}{l}\text { Establecer un manual de proces } \\
\text { para la mejora de la actividad } \\
\text { conjunto entre departamentos } \\
\text { lapso de } 2 \text { años. }\end{array}$ & & & $\begin{array}{l}\text { ivel de ar } \\
\text { el } \\
\text { lanual de } \\
\text { ctividad } \\
\text { onjunto } \\
\text { el } \\
\text { anunal de } \\
\text { ctividad } \\
\text { onjuntoe }\end{array}$ & $\begin{array}{l}\text { avance del } \\
\text { e proceso } \\
\text { entre dep } \\
\text { e proceso } \\
\text { entre dep }\end{array}$ & $\begin{array}{l}\text { I manual } \\
\text { ss para la } \\
\text { arrtamen } \\
\text { os para la } \\
\text { cartamen }\end{array}$ & $\begin{array}{l}\text { I de proce } \\
\text { a mejora } \\
\text { ntos / Tot } \\
\text { a mejora } \\
\text { ntos }\end{array}$ & $\begin{array}{l}\text { esos = Eta } \\
\text { de la } \\
\text { tal de etar } \\
\text { de la }\end{array}$ & & $\begin{array}{l}\text { Nivel de } \\
\text { manual d }\end{array}$ & $\begin{array}{l}\text { avance del } \\
\text { e procesos }\end{array}$ & & Anual & & nforme de $\mathrm{g}$ & gerencia & 0 \\
\hline & & & & & & & & IMER & NIVE & & & & & & & & & & \\
\hline Perspectivas & & AREA & O UNIDAD & & & & & & & & & MEtAS & & & & & & & \\
\hline & Estrategia de Valor & & Objetivos Estratégicos & 0 & ic, 2021 & $\bullet$ & 0 & $\begin{array}{ll}\text { Dic, } 2022 \\
\mathrm{O}\end{array}$ & $\bullet$ & 0 & Dic, 2023 & $\bullet$ & \begin{tabular}{l|l} 
Dic, \\
0 & $C$ \\
\end{tabular} & $\begin{array}{cc}\mathrm{i}, 2024 \\
\mathrm{O}\end{array}$ & $\bullet$ & 0 & $\begin{array}{ll}\text { Dic, } 2025 \\
0 \\
\end{array}$ & $\bullet$ & $\begin{array}{c}\text { Responsable de } \\
\text { la meta }\end{array}$ \\
\hline & $\begin{array}{l}\text { Estrategia de } \\
\text { productividad }\end{array}$ & $\begin{array}{l}\text { Aument } \\
\text { dentro }\end{array}$ & $\begin{array}{l}\text { tar en 45\% la cartera de clientes } \\
\text { de } 5 \text { años. }\end{array}$ & $=1133$ & $>=1086$ & 1.039 & $>=1.226$ & $>=1.180$ & 1.133 & $=1.320$ & $>=1.273$ & 1.226 & \begin{tabular}{|l|l}
$\mid=1.413$ & 1
\end{tabular} & 1.367 & $1.320=$ & $>=1.507$ & $x=1.460$ & 1.413 & Gerente general \\
\hline Financiera & $\begin{array}{l}\text { Estrategia de } \\
\text { crecimiento }\end{array}$ & $\begin{array}{l}\text { Increme } \\
\text { de la en } \\
\text { de } 5 \text { añ }\end{array}$ & $\begin{array}{l}\text { lentar el rendimiento sobre capital } \\
\text { mpress en } 10 \% \text { dentro de un lapso } \\
\text { ios. }\end{array}$ & $>=74 \%$ & $>=73 \%$ & $72 \%$ & $s=76 \%$ & $>=75 \%$ & 74,00\% & $>=78 \%$ & $>=77 \%$ & $76 \%$ & $>=80 \% \mid>=$ & $>=79 \%$ & $78 \%$ & $>=82 \%$ & $>=81 \%$ & $80 \%$ & Gerente general \\
\hline & Estrategia de calidad & $\begin{array}{l}\text { Diseñar } \\
\text { para pie } \\
\text { provenin } \\
\text { contine }\end{array}$ & 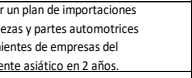 & 0 & 0 & 0 & 1 & 1 & 0 & & & & & & & & & & Gerente general \\
\hline $\begin{array}{c}\text { Perspectiva del } \\
\text { cliente }\end{array}$ & strategia de selección & $\begin{array}{l}\text { Implem } \\
\text { piezas } y \\
\text { de la ca } \\
\text { de engr } \\
\text { plumas }\end{array}$ & $\begin{array}{l}\text { nentar tres nuevas lineas de } \\
\text { y partes automotrices dentro } \\
\text { artera de productos (sistema } \\
\text { ranaje, sistema de bateríasy } \\
\text { limpiaparabrisas) en } 3 \text { añosos. }\end{array}$ & $z=6$ & $>=5,5$ & 5 & $>=7$ & $>=6,5$ & 6 & $x=8$ & $>=7,5$ & 7 & & & & & & & Gerente general \\
\hline & :strategia de servicio & $\begin{array}{l}\text { Implem } \\
\text { venta en } \\
\text { Sector }\end{array}$ & $\begin{array}{l}\text { nentar un nuevo punto de } \\
\text { "n el Km2 de la Av. Quevedo } \\
\text { "La Pepsi" en } 2 \text { años. }\end{array}$ & 0 & 0 & 0 & $={ }^{1}$ & $={ }^{1}$ & $=0$ & & & $=$ & & & & & & & Gerente general \\
\hline & $\begin{array}{c}\text { strategia de gestión } \\
\text { operativa }\end{array}$ & $\begin{array}{l}\text { Desarro } \\
\text { servicio } \\
\text { relacion } \\
\text { de 2 2añ }\end{array}$ & $\begin{array}{l}\text { ollar un plan integral de } \\
\text { o posventa para mejorar las } \\
\text { nes con el cliente en el lapso } \\
\text { ios. }\end{array}$ & 0 & 0 & 0 & $={ }_{1}$ & ${ }_{1}$ & $=0$ & & & & & & & & & & Gerente general \\
\hline $\begin{array}{l}\text { Perspectiva } \\
\text { Interna }\end{array}$ & $\begin{array}{l}\text { :strategia de gestión } \\
\text { de cliente }\end{array}$ & $\begin{array}{l}\text { Implem } \\
\text { créditos } \\
\text { paga a } \\
\text { frecuen } \\
\text { de prod }\end{array}$ & $\begin{array}{l}\text { mentar un programa de } \\
\text { sp para otorgar facilidades de } \\
\text { clientes con compras } \\
\text { ntes y determinada cantidad } \\
\text { ductos en } 1 \text { año. } \\
\end{array}$ & $=1$ & $=1$ & $=0$ & & & & & & & & & & & & & Gerente general \\
\hline & $\begin{array}{l}\text { :strategia de estión } \\
\text { de cliente }\end{array}$ & $\begin{array}{l}\text { Implem } \\
\text { asesora } \\
\text { de } 2 \text { añ }\end{array}$ & $\begin{array}{l}\text { nentar un programa de } \\
\text { amiento a clientes en un lapso } \\
\text { jos. }\end{array}$ & 0 & 0 & 0 & $={ }^{1}$ & $={ }^{1}$ & $={ }^{0}$ & & & & & & & & & & Area de ventas \\
\hline & $\begin{array}{l}\text { Estrategia de capital } \\
\text { humano }\end{array}$ & $\begin{array}{l}\text { Desarro } \\
\text { incentiv } \\
\text { permita } \\
\text { conlac }\end{array}$ & $\begin{array}{l}\text { ollar un programa de } \\
\text { vos a los trabajadores que } \\
\text { a aumentar su compromiso } \\
\text { organización en } 1 \text { año. }\end{array}$ & $={ }^{1}$ & $={ }^{1}$ & $={ }^{0}$ & & & & & & & & & & & & & Gerente general \\
\hline $\begin{array}{l}\text { Perspectiva de } \\
\text { Aprendizaje }\end{array}$ & $\begin{array}{l}\text { Estrategia de capital } \\
\text { humano }\end{array}$ & $\begin{array}{l}\text { Implem } \\
\text { persona } \\
\text { empres. }\end{array}$ & $\begin{array}{l}\text { nentar un plan de capacitaciones al } \\
\text { ala administratvo yoperativo de la } \\
\text { sa en un lapso de } 2 \text { años. }\end{array}$ & 0 & 0 & 0 & $=1$ & $={ }^{1}$ & $={ }^{0}$ & & & & & & & & & & Gerente general \\
\hline & $\begin{array}{l}\text { Estrategia de cultura } \\
\text { organizacional }\end{array}$ & $\begin{array}{l}\text { Estable } \\
\text { para la } \\
\text { coniunt } \\
\text { lajsoso de }\end{array}$ & 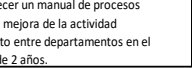 & 0 & 0 & 0 & 1 & 1 & 0 & & & & & & & & & & Gerente general \\
\hline
\end{tabular}

Fuente: Datos obtenidos de la investigación "Importadora de Autorepuestos Mendoza" 
Tabla 8. Balanced Scoredcard 2do nivel "Importadora de Autorepuestos Mendoza"

\begin{tabular}{|c|c|c|c|c|c|}
\hline PERSPECTIVA & $\begin{array}{c}\text { OBJETIVO } \\
\text { ESTRATEIEICO -1N }\end{array}$ & OBJETIVO DE SEGUNDO NIVEL & KPI's & Definición Operacional & Fuente de captura \\
\hline \multirow{5}{*}{ FINANCIERA } & \multirow{3}{*}{$\begin{array}{l}\text { Aumentar en } 45 \% \text { la cartera } \\
\text { de clientes dentro de } 3 \text { años }\end{array}$} & 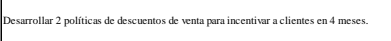 & 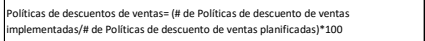 & 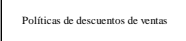 & Informe Árca de compras y yentas \\
\hline & & $\begin{array}{l}\text { Diseñar un plan de marketing operativiv para la empressa Importadodra de } \\
\text { Autorefenuestos Mendoza e } 3 \text { meses. }\end{array}$ & Plan de marketing = \# de etapas jejectadas/ / de etapas planificicadas & Plan de marketing & Informe de arances plan de markcting \\
\hline & & $\begin{array}{l}\text { Implementar una página web que permita a los usuarios tener acceso a } \\
\text { información de la empresa en } 3 \text { meses. }\end{array}$ & Página web= \# de módulos implementados / \# de módulos planificados & Página web & Informe de gerencia \\
\hline & \multirow{2}{*}{$\begin{array}{l}\text { Incrementar el rendimiento } \\
\text { sobre el capital de la } \\
\text { empresa en } 10 \% \text { dentro de } \\
\text { un lapso de } 3 \text { años. }\end{array}$} & $\begin{array}{l}\text { Realizar un estudio para la identificación de entidades financieras que permitan } \\
\text { presstamos banacrios en } 4 \text { meses. }\end{array}$ & 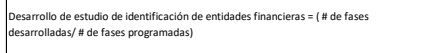 & 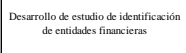 & Informe de gerencia \\
\hline & & $\begin{array}{l}\text { Establecer una alianza con una entidad bancaria para la obtención de crédito a } \\
\text { microempressas dentro de } 3 \text { meses. }\end{array}$ & Alianzas estratégicas $=\mathrm{N}^{\circ}$ de alianzas estartégicas desarrolladas & Alianzas estratégicas & Documento de gerencia \\
\hline \multirow{8}{*}{ CLIENTES } & \multirow{3}{*}{ 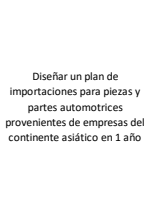 } & 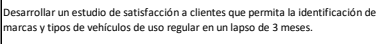 & Estudio satisfacción al cliente = (" de fases desarrolladass/ / de fases programadas) & Estudio satistacción a lcliente & Informe de área de comprass y ventus \\
\hline & & 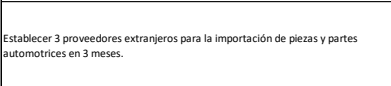 & Proveedores extranjeros $=\mathrm{N}^{*}$ total de nuevos proveedores & Provecedores extranjeros & $\begin{array}{l}\text { Reporte de provecdores extranjeros } \\
\text { seleccionados }\end{array}$ \\
\hline & & $\begin{array}{l}\text { Contratar una agencia intermediaria dedicada a ejecucicin de procedimimentos } \\
\text { aduaneros en un lapso de } 3 \text { meses. }\end{array}$ & Contratación de empresas aduaneras $=N^{*}$ de empresas contratadas & Contrataxiön de empresesa a duaneras & Documento de gerencia \\
\hline & 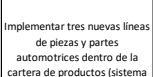 & \begin{tabular}{|l} 
Elaborara un estudio de mercrado para determinar los potenciales clientes del \\
sistema de engranaje, baterias y plumas limpliaparbabissas en 4 meses.
\end{tabular} & $\begin{array}{l}\text { Desarrollo de estudio de mercrado = (" de fe fases de estudio de mercado realizadas/Total } \\
\text { de fases de estudio de mercado programadas) }\end{array}$ & Dessurollo de estudio de mercado & $\begin{array}{l}\text { Informe cetapus de cestudio de mercato } \\
\text { realizadis }\end{array}$ \\
\hline & 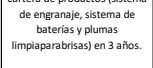 & $\begin{array}{l}\text { Establecer un plan de convenios con provededores de las lineas de piezas } \\
\text { automotrices en } 4 \text { meses. }\end{array}$ & 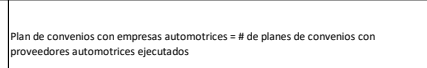 & $\begin{array}{l}\text { Plan de convenios con empressis } \\
\text { automolicices }\end{array}$ & Documento de gerencia \\
\hline & \multirow{3}{*}{$\begin{array}{l}\text { Implementar un nuevo punto } \\
\text { de venta en el Km2 de la Av. } \\
\text { Quevedo Sector "La Pepsi" en } 2 \\
\text { años. }\end{array}$} & 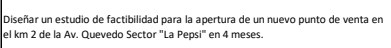 & 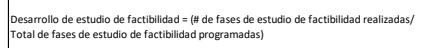 & Desarrollo de estudio de fectibibilidad & 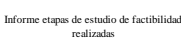 \\
\hline & & Establecer un manual de recutuamiento y selección de personal en 3 meses. & $\begin{array}{l}\text { Nivel de avance del manual = Etapas del manual de reclutamiento y selección del } \\
\text { personal/ Total de etapas del manual de reclutamiento y seleccion de personal }\end{array}$ & Nivel de arance del manual & Documento de gerencia \\
\hline & & Contratar dos nuevos vendedodres para el nuevo punto de venta dentro de 2 meses & $\begin{array}{l}\text { Contratacíón de vendedores =\# de nuevos vendedores contratados/Total de } \\
\text { vendedores }\end{array}$ & Contratación de vendedoress & Informe Ára de compras y y ventas \\
\hline
\end{tabular}

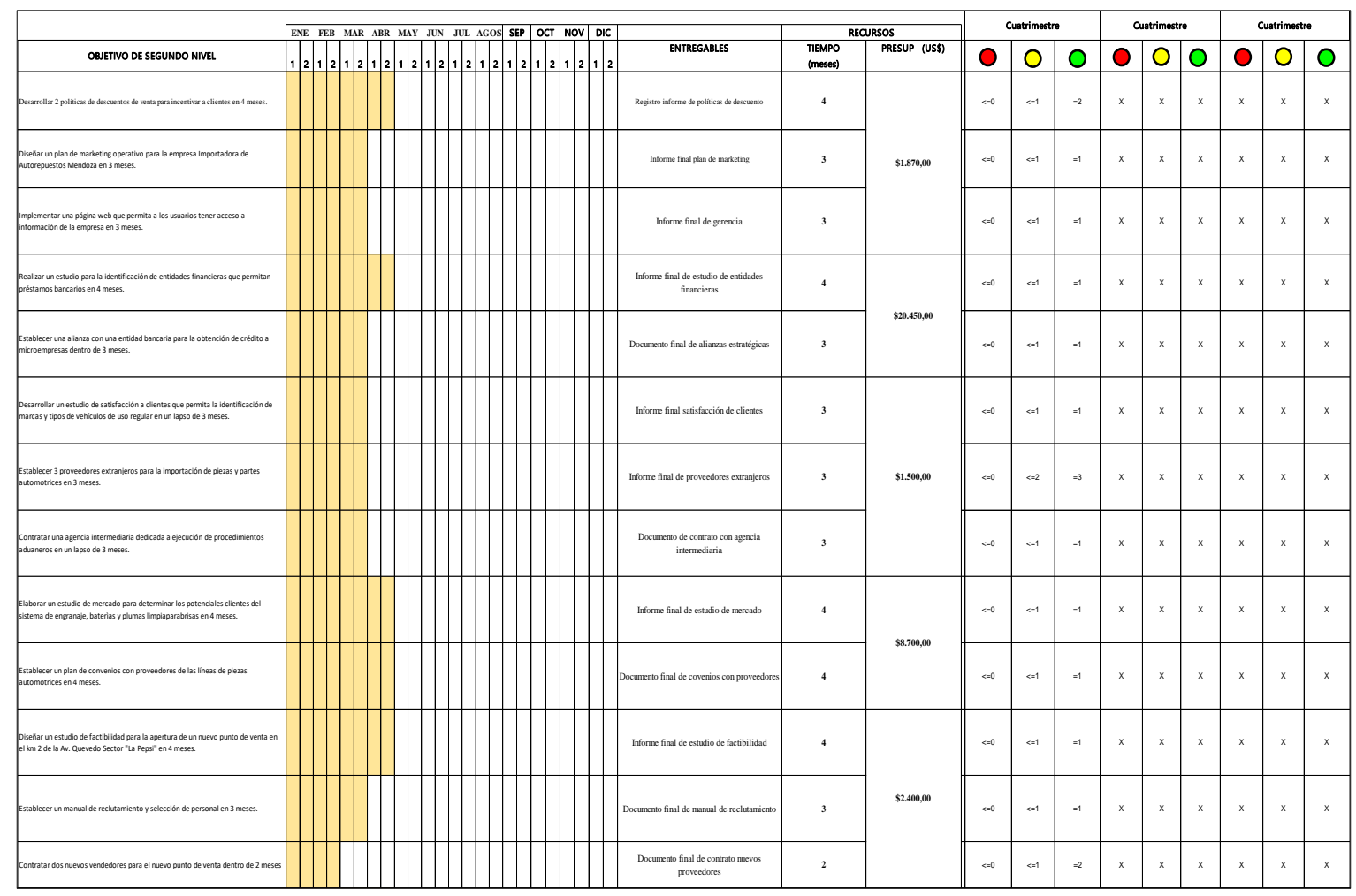

Fuente: Datos obtenidos de la investigación "Importadora de Autorepuestos Mendoza" 


\section{DISCUSIÓN Y CONCLUSIONES}

La Importadora de Autorepuestos Mendoza presenta una situación adversa con respecto a la toma de decisiones de manera empírica, con lo cual, a pesar de que no ha implementado ningún tipo de estrategias, proyectos o iniciativa, se ha mantenido en el mercado del sector automotriz durante 9 años consecutivos.

Para la elaboración del plan estratégico de desarrollo institucional en la organización, Davara (2015) indica que "se define como un proceso de decisión que debe conducir a seleccionar las estrategias a poner en práctica con objeto de alcanzar los objetivos establecidos” (p.159). Es así que, la identificación de factores internos y externos permiten determinar las características favorables y desfavorables que presenta la organización con respecto a sus procesos, utilización de recursos financieros, y fuentes de ingreso.

Con lo dicho anteriormente, la empresa Importadora de Autorepuestos Mendoza evidencia una problemática significativa con respecto a la inexistencia de procedimientos para la reposición de inventario, así como también, la falta de políticas de recuperación de cartera, inadecuada delimitación de funciones, direccionamiento estratégico y un foco estratégico definido. Estas limitaciones son semejantes a la investigación "La planificación estratégica como herramienta de desarrollo de las empresas agropecuarias en el Ecuador" las cuales no cuentan con procesos internos que potencialicen las actividades primordiales de estas organizaciones.

La aplicación de recolección de datos mediante una entrevista al gerente, un test organizacional y una encuesta a clientes externos, permite tener una percepción más clara de la situación actual de la empresa, y establecer prioridades al momento de desarrollar estrategias de mejor continua.

Dentro del sector comercial, es primordial establecer metas u objetivos a largo y corto plazo en la actualidad, ya que permite establecer una mayor eficiencia, eficacia y efectividad en los procesos internos, así como también, identificar las principales oportunidades y amenazas en el mercado. Un claro ejemplo en el Ecuador, es el caso que se desarrolló sobre la aplicación de planificación estratégica en las pequeñas y medianas empresas de Quito, para determinar el nivel de inclusión y aplicación en la realidad de este tipo de organizaciones, del cual se obtuvo como resultado que el 94\% de 267 empresas analizadas, tienen por escrito un plan estratégico, y únicamente el $22 \%$ de estas organizaciones lo implementan de manera integral.

Para la implementación de la estrategia Balanced Scoredcard de 1er y 2do nivel, según Kaplan \& Norton (2002) señala que "proporciona un marco, una estructura y un lenguaje para comunicar la misión y la estrategia; utiliza las mediciones para informar a los empleados sobre los causantes del éxito actual y futuro" (p.37). De modo que, el cuadro de mando integral sirve para dar a conocer a cada uno de los 
stakeholders, la manera en que el diseño de una estructura basado en estrategias, beneficiará de manera directa a las actividades de la organización.

El desarrollo del Balanced Scoredcard para la empresa Importadora de Autorepuestos Mendoza se basa en 11 objetivos estratégico con respecto a la mejora de procesos internas y externos de la organización. El nivel directivo debe incentivar al cumplimiento de las metas establecidas a los niveles operativos, de tal manera se promueve la utilización eficaz de las herramientas administrativas.

Dentro del diagnóstico situacional en la Importadora de Autorepuestos Mendoza se identificó que, a pesar de la inexistencia de planificación previa en sus actividades, se obtuvo una liquidez de \$1,96 en el año 2019 lo cual representa una situación favorable para la organización. Por el contrario, la empresa cuenta con un endeudamiento de $49 \%$ que se genera por la reposición de inventario en el 2019. De la misma forma, se identifica que, la ineficiencia en los procesos internos genera confusión en el ingreso de mercadería y búsqueda de productos en inventario. Para el análisis Pestel, se presentan principales amenazas con respecto a importación de productos de los principales aliados de Ecuador, China y Estados Unidos de América presentan un decrecimiento en sus economías y producción nacional.

La propuesta de implementación de la estrategia permitió identificar 11 objetivos multinivel alineados a la visión empresarial, mediante la perspectiva de crecimiento y aprendizaje, procesos internos, clientes y financiera que, posteriormente, se desarrollan 30 objetivos a corto plazo, con políticas y reglas establecidas en el Plan Estratégico de Desarrollo Institucional (PEDI).

Para la evaluación de los objetivos estratégicos se diseñó la herramienta de gestión administrativa Balanced Scoredcard de 1er y 2do nivel que proporciona un marco general del cumplimiento de las metas a través de KPI'S, con el fin de dar cumplimiento a la visión general de la empresa. 


\section{REFERENCIAS}

Agencia de Noticias de Francia. (05 de Enero de 2021). La recuperación económica en China fortalece el yuan frente al dólar. Obtenido de https://www.france24.com/es/minuto-a-minuto/20210105-larecuperaci\%C3\%B3n-econ\%C3\%B3mica-en-china-fortalece-el-yuan-frente-al-d\%C3\%B3lar

Asociación de Empresas Automotrices del Ecuador. (20 de Febrero de 2020). Anuario 2019. Obtenido de https://www.aeade.net/wp-content/uploads/2020/07/AEADE-ANUARIO-2019-OK_1.pdf

Banco Central del Ecuador. (30 de Noviembre de 2020). La economía ecuatoriana se recuperará 3,1\% en 2021. Obtenido de https://www.bce.fin.ec/index.php/boletines-de-prensa-archivo/item/1394-laeconomia-ecuatoriana-se-recuperara-3-1-en-2021\#_ftnref1

Banco Mundial. (03 de Enero de 2019). Grupo Banco Mundial. Obtenido de Marco de Cooperación con Ecuador : http://documents1.worldbank.org/curated/en/320261577466362319/pdf/Ecuador-CountryPartnership-Framework-for-the-Period-of-the-FY19-FY23.pdf

Beltrán, M., Andrade, C., \& Gómez, C. (2016). Proceso de desarrollo de productos en los Núcleos de innovación fundamentado en el modelo de Stage Gate con retroalimentación de mercado. Revista Gestión de las personas y tecnología, 58-71.

Cámara de Comercio de Quito. (01 de Mayo de 2020). Reporte Comercio Exterior Ecuador. Obtenido de https://ccq.ec/wp-content/uploads/2020/05/ReporteComercioExterior-CCQ05.pdf

Carvajal, G., Almeida, E., Lemoine, F., Caicedo, E., Zambrano, L., Pisco, J., \& Nogueira, D. (2021). Control de la gestión del destino turístico sucre-san vicente -jama -pedernales, caso observatorio turístico. South Florida Journal of Development, 2451-2461.

Carrillo, E., Rodriguez, Á., \& Arellano, M. (2020). La planificación estratégica como herramienta de desarollo de las empresas en el Ecuador. 181-203.

Castillo, G., \& Banguera, D. (2018). Evaluación estratégica desde una matriz FODA en la empresa aglomerados . Revista multidisciplinar de innovación y estudios aplicados , 224-230.

Centro de Comercio Internacional . (29 de Enero de 2021). Trade Map. Obtenido de https://www.trademap.org/Index.aspx

Comité de Comercio Exterior. (10 de Diciembre de 2018). El Pleno del Comité de Comercio Exterior. Obtenido de Resolución No. 025-2018: https://www.produccion.gob.ec/wpcontent/uploads/2019/06/Resolucio\%CC\%81n-025-2018.pdf

Cremades, A., \& Bianchi, M. (15 de Abril de 2016). Oficina Económica y Comercial de la Embajada de España en Quito. Obtenido de El mercado de repuestos para automóviles en Ecuador: http://www.siicex.gob.pe/siicex/documentosportal/alertas/documento/doc/884641079radBFA4B.pdf

Davara, F. (2015). Planificación estratégica e inteligencia económica: herramientas de gestión del cambio . Cuadernos de estrategia , 189-229.

David, F. (2013). Conceptos de administración estratégica . México : PEARSON EDUCATION . 
Fong, C. (2017). Las teorías de la ventaja competitiva . Revista científica de la Universidad de Guadalajara , 29-77.

Hernández, R., Fernández, C., \& Baptista, M. (2010). Metodología de la investigación . México D.F : McGraw-Hill / INTERAMERICANA EDITORES S.A DE C.V.

Hernández, R., Fernández, C., \& Baptista, P. (2014). Metodología de la Investigación. México DF: McGraw - HILL Education.

Ibarra, M., Gonzalez, L., \& Demuner, M. (2017). Competitividad empresarial de las pequeñas y medianas empresas manufactureras de Baja California. Estudios fronterizos, 107-130. doi:https://doi.org/10.21670/ref.2017.35.a06

IICA. (2018). Gestión empresarial estratégica: El análisis interno y externo . San José: Instituto Interamericano de Cooperación para la agricultura .

Instituto Nacional de Estadísticas y Censos . (01 de Diciembre de 2020). Anuario de estadísticas de transporte 2019. Obtenido de https://www.ecuadorencifras.gob.ec/documentos/webinec/Estadisticas_Economicas/Estadistica\%20de\%20Transporte/2019/2019_ANET_PPT.pdf

Instituto Nacional de Estadísticas y Censos . (30 de Abril de 2020). Boletín Técnino $N^{\circ} 01-2020-E N E S E M$. Obtenido de https://www.ecuadorencifras.gob.ec/documentos/webinec/Estadisticas_Economicas/Encuesta_Estructural_Empresarial/2018/2018_ENESEM_Boletin_tecnic o.pdf

Kaplan, R., \& Norton, D. (2004). Mapa estratégico: Convirtiendo los activos intangibles en resultados tangibles. Barcelona : Ediciones Gestión 2000.

Maldonado, J. (2018). Metodología de la investigación social: Paradigmas: cuantitativo, sociocrático, cualitativo, complementario. Bogotá : Ediciones de la U .

Melendez, L., Vergel, M., \& Martínez, J. (2017). Estrategia organizacional y adopción de práctivas saludables en la región Caribe de Colombia . Revista Logos, Tecnología \& Ciencia , 179-196.

Ministerio de Electricidad y Energía Renovable. (16 de Octubre de 2016). Plan Nacional de Eficiencia Energética 2016--2035. Obtenido de https://www.cnelep.gob.ec/wpcontent/uploads/2017/09/1.PLAN_NACIONAL_EFICIENCIA_ENERGETICAmaqueta-finaldigital.pdf

Ministerio de Producción Comercio Exterior Inversiones y Pesca . (04 de Diciembre de 2020). Estructura y firma del Acuerdo de Primera Fase con Estados Unidos es la ruta hacia un convenio comercial integral. Obtenido de https://www.produccion.gob.ec/estructura-y-firma-del-acuerdo-de-primera-fase-conestados-unidos-es-la-ruta-hacia-un-convenio-comercial-integral/

Ministerio de Producción, Comercio Exterior, Inversiones y Pesca. (25 de Febrero de 2019). ACUERDO Nro. MPCEIP-DMPCEIP-2019-0017 .

Ministerio de Transporte y Obras Públicas. (01 de Julio de 2019). Elaboración de la Política Nacional de Movilidad Urbana Sostenible - PNMU de Ecuador. Obtenido de https://www.obraspublicas.gob.ec/wpcontent/uploads/downloads/2019/07/STT_Euroclima_Solicitud-de-Expresion-de-Interes.pdf 
Mora, E., Vera, M., \& Melgarejo, Z. (2015). Planificación estratégica y niveles de competitividad de las Mipymesdel sector comercio en Bogotá. Estudios gerenciales, 79-87. doi:http://dx.doi.org/10.1016/j.estger.2014.08.001

Nieves, M. (2018). Origen y evolución de la matriz tows en la administración estratégica del siglo XXI. Revista Administración y Finanzas , 8-27.

Ochoa, C., Sanchez, A., Hidalgo, H., \& Medina, D. (2018). El análisis financiero como herramienta clase para una gestión financiera de las medianas empresas comerciales dek Cantón Milagro . Revista eumednet, $1-19$.

Palacios, A., Mantilla, D., Arévalo, P., Guadalupe, J., \& Cevallos, M. (2017). Grado de utilización de los elementos integrantes de la planeación estratégica en las PYMES de Quito. CienciAmérica , 7-14.

Registro Oficial Órgano del Gobierno del Ecuador. (19 de Marzo de 2019). Ley Orgánica de Eficiencia Energética . Obtenido de https://www.recursosyenergia.gob.ec/wpcontent/uploads/downloads/2019/03/Ley-Eficiencia-Energe\%CC\%81tica.pdf

Rivas, Y., Reyes, I., Adrían, A., \& Vasquez, P. (2018). Construcción de la cadena de valor genérica en la unidad empresarial de base "Cárnico Bayamo". Provincia Granma, Cuba. Revista eunmednet, 3-20.

Rodríguez, C. (2016). Planificación y apertura de un pequeño comercio . Madrid: Editorial CEP. Sainz, J. (2017). El plan estratégico en la práctica . México : ESIC Editorial .

Secretaría Nacional de Planificación y Desarrollo. (01 de Enero de 2017). Plan Nacional de Desarrollo 2017-2021 Toda una Vida. Obtenido de https://www.planificacion.gob.ec/wpcontent/uploads/downloads/2017/10/PNBV-26-OCT-FINAL_0K.compressed1.pdf

Senplades. (2017). Toda una vida: Plan Nacional de Desarrollo 2017-2021. Quito.

Valladares, C., Sánchez, K., Ugando, M., Sabando, A., \& Villalón, A. (2021). Gestión de capital de trabajo y su efecto en la rentabilidad para el grupo de empresas del sector manufacturero ecuatoriano. South Florida Journal Development. Miami, v. 2, n.2 apr./jun.p.

DOI: https://doi.org/10.46932/sfjdv2n2-075

Villa, E., Pons, R., Bermúdez, Y., \& Pérez, H. (2020). Procedimiento para el diseño de escalas de medición e indicadores de control de la gestión de las competencias de procesos clave. South Florida Journal of Development, 1134-1145.

Zapata, G., \& Mirabal, A. (2018). Capacidades Dinámicas de la Organización: Revisión de la Literatura y un modelo Propuesto . 110-121. 